\title{
Biosensing of periprocedural events in acute ST- segment elevation myocardial infarction patients with the erythrocyte-derived microparticles
}

\author{
Alexander E. Berezin* \\ Department of Internal Medicine, Medical University, Zaporozhye, Ukraine
}

\begin{abstract}
The short commentary is depicted the role of the circulating number of red blood cell (RBC) microparticles (MPs) as predictive biomarker in acute myocardial infarction patients after primary percutaneous coronary intervention (PCI). The commonly used cardiac biomarkers (i.e., troponins, creatine kinase-myocardial band isoenzymes, myoglobin, heart-type fatty acid-binding protein, copeptin and B-type natriuretic peptide) have now exhibited broad spectrum limitations regarding short-term and long-term-term mortality rate. Recent clinical studies have shown that the number of RBC-MPs has increased in acute myocardial infarction as compared to healthy volunteers and patients with unstable angina, associated with the extent of myocardial damage and have potential adverse vascular and thrombotic effects. It has been suggested that the number of RBC-MPs might be better predictor compared to other cardiac biomarkers in scintigraphically measured infarct size, periprocedural left ventricular ejection fraction and survival rate.
\end{abstract}

Microvascular obstruction has remained a prognostic importance for short-term and long-term periprocedural survival after acute STsegment elevation myocardial infarction (STEMI) [1,2]. Although there is a large body of evidence regarding utility of biomarkers of cardiac injury in predicting myocardial functional recovery [3-5], the prognostic information of commonly used cardiac biomarkers (i.e., troponins, creatine kinase-myocardial band isoenzymes, and their combinations) regarding mortality rate is still controversial [68]. Indeed, troponin I is an highly sensitive marker of myocardial necrosis or even very minor reversible myocardial injury caused by percutaneous coronary intervention (PCI), which did not influence the death rate [9].

However, in the Selective Inhibition of Delta-protein Kinase $\mathrm{C}$ for the Reduction of Infarct Size in Acute Myocardial Infarction (PROTECTION-AMI) trial were determined that only baseline left ventricular ejection fraction (LVEF), infarct size and infarct heterogeneity independently predicted 90-day LVEF, though other biomarkers did not [3]. In the EVOLVE (Evaluation Of MCC-135 for Left Ventricular Salvage in Acute Myocardial Infarction) trial, elevated troponin $\mathrm{T}$ level was associated with increased 180-day composite clinical events and independently predicted several adverse events, but not death [10]. In contrast, Gollop et al. [11] reported that an elevation in CK-MB was best predictor of adverse events including death compared with troponins in post-PCI individuals. Thus, actual findings suggest that cardiac biomarker of injury (i.e., troponins, creatinine kinase $\mathrm{MB}$ isoenzyme, and probably myoglobin) might no longer be the optimal early predictors in STEMI patients undergoing primary PCI, while they are able to depict worsening myocardial perfusion, myocardial infarct size, cardiac function and postponed left ventricular remodeling. Moreover, as a prognostic marker, creatinine kinase MB isoenzyme measured on admission was superior to cardiac troponin using a high-sensitivity assay, NTproBNP measurement on admission, but myoglobin, heart-type fatty acid-binding protein, copeptin and B-type natriuretic peptide were prognostically equivalent [12]. Consequently, to improve predictive approaches based on biomarker measurement in PCI patients, discovery of novel biomarkers maximally attributed solely to each individual after PCI is required. Formerly cell-derived microparticles (MPs) were determined as cell debris without any diagnostic and predictive information, but now they are considered biomarkers in cardiovascular and metabolic disease including atherosclerosis, unstable angina pectoris, hypertension, heart failure, arrhythmia, thromboembolism, metabolic syndrome, and diabetes, as well as in subjects with implanted cardiac assist devices [11,13-22].

The majority investigations have now addressed to the endothelial cell-derived MPs, which are marker of endothelial dysfunction and cardiovascular death $[23,24]$, while MPs originated from other cells (i.e., red blood cells) have exhibited a relation to severity of atherosclerosis and coronary obstruction [25]. Recent studies have shown that the circulating number of endothelial cell-derived MPs originated from activated or apoptotic cells may be markers with powerful independent predictive value in patients with acute myocardial infarction after PCI, although utility of endothelial cell-derived MP measurement is not strongly determined [26]. However, it has suggested that endothelial cell-derived MP assay could be incorporated into multiple biomarkers strategy based on troponins and creatinine kinase MB isoenzyme measurement to improve risk stratification for cardiovascular events

Correspondence to: Alexander E. Berezin, Consultant of Therapeutic Unit, Department of Internal Medicine, Medical University, Zaporozhye, Ukraine, Tel: +380612894585; E-mail: dr_berezin@mail.ru, aeberezin@gmail.com

Key words: acute myocardial infarction, primary percutaneous coronary intervention, cardiac biomarkers, red blood cell microparticles, prognosis

Received: January 05, 2017; Accepted: January 20, 2017; Published: January 23, 2017 
in patients at high risk for cardiac death and cardiovascular events [27].

The number of red blood cell (RBC) MPs has increased in acute myocardial infarction as compared to healthy volunteers and patients with unstable angina and probably associated with the extent of myocardial damage. RBC-MPs have potential adverse vascular effects and they have been shown to be elevated in ST elevation myocardial infarction (STEMI) [28]. There is evidence regarding close relationship between circulating number of RBC-MPs and biochemical infarct size, circulating troponins and reverse of ischemia-induced myocardial dysfunction [28], although the exact pathophysiologic routes for these interactions remain to be uncertain. Probably, pro-coagulant thrombotic activity of RBC-MPs and their ability inducing platelet activation and aggregation might explain the role of them in the pathogenesis of periprocedural microvascular obstruction and left ventricular remodeling $[29,30]$. Therefore, RBC-MPs are able to activate endothelium in visceral organs and thereby influence vasoconstriction and direct injury of them [31,32]. Finally, RBC-MPs are player in the myocardial reperfusion injury, which attenuates the benefit of PCI after acute myocardial infarction. Whether RBC-MPs would be potentially useful for risk stratification after primary PCI is not fully clear. Therefore, it is not understood whether RBC-MP count would be prognostically superior to high-sensitivity cardiac troponins, creatinine kinase MB isoenzyme, myoglobin, natriuretic peptides, copeptin, heart-type fatty acid-binding protein, and scintigraphically measured infarct size, which remains a better correlate of 1-year mortality than either biomarkers. However, measurement of circulating RBC-MP number after primary PCI appears to be promising because lack of individualized biomarkers with predictive value regarding survival in subjects with microvascular obstruction remains to be challenged. All these findings require more investigations in future.

\section{Conclusion}

There are no strong evidence regarding the advantages of periprocedural use of RBC-MPs compared to widely used biomarkers including high-sensitivity cardiac troponins, creatinine kinase $\mathrm{MB}$ isoenzyme during PCI to provide prognostic information about the degree of myocardial injury and risk of morbidity and mortality. However, the need of discovery of novel biomarker with higher predictive value is obvious fact. RBC-MPs could be discussed as attempt to individualize risk stratification amongst acute ST-segment elevation myocardial infarction patients after primary PCI, because other routinely used biomarkers have exhibited some serious limitations. In future, more investigations are required to explain in detail the role of the number of RBC-MPs in prediction of survival amongst acute STsegment elevation myocardial infarction patients after primary PCI.

\section{Funding}

This research received no specific grant from any funding agency in the public, commercial, or not-for-profit sectors.

\section{Conflict of interests}

None declared

\section{References}

1. Crimi G, Pica S, Raineri C, Bramucci E, De Ferrari GM, et al. (2013) Remote ischemic post-conditioning of the lower limb during primary percutaneous coronary intervention safely reduces enzymatic infarct size in anterior myocardial infarction: a randomized controlled trial. JACC Cardiovasc Interv 6: 1055-1063. [Crossref]

2. Brener SJ, Maehara A, Dizon JM, Fahy M, Witzenbichler B, et al. (2013) Relationship between myocardial reperfusion, infarct size, and mortality: the INFUSE-AMI
(Intracoronary Abciximab and Aspiration Thrombectomy in Patients with Large Anterior Myocardial Infarction) trial. JACC Cardiovasc Interv 6: 718-724. [Crossref]

3. Grover S, Bell G, Lincoff M, Jeorg L, Madsen PL, et al. (2015) Utility of CMR Markers of Myocardial Injury in Predicting LV Functional Recovery: Results from PROTECTION AMI CMR Sub-study. Heart Lung Circ 24: 891-897. [Crossref]

4. Loeb HS, Liu JC (2010) Frequency, risk factors, and effect on long-term survival of increased troponin I following uncomplicated elective percutaneous coronary intervention. Clin Cardiol 33: E40-4. [Crossref]

5. Natarajan MK, Kreatsoulas C, Velianou JL, Mehta SR, Pericak D, et al. (2004) Incidence, predictors, and clinical significance of troponin-I elevation without creatine kinase elevation following percutaneous coronary interventions. Am J Cardiol 93: 750753. [Crossref]

6. Jang JS, Jin HY, Seo JS, Yang TH, Kim DK, et al. (2012) Prognostic value of creatine kinase-myocardial band isoenzyme elevation following percutaneous coronary intervention: a meta-analysis. Catheter Cardiovasc Intervent 81: 959-967. [Crossref]

7. Testa L, Van Gaal WJ, Biondi Zoccai GG, Agostoni P, Latini RA, et al. (2009) Myocardial infarction after percutaneous coronary intervention: a meta-analysis of troponin elevation applying the new universal definition. QJM 102: 396-378. [Crossref]

8. Cavallini C, Savonitto S, Violini R, Arrraiz G, Plebani M, et al. (2005) Impact of the elevation of biochemical markers of myocardial damage on long-term mortality after percutaneous coronary intervention: results of the CK-MB and PCI study. Eur Heart $J$ 26: 1494-1498. [Crossref]

9. Chia S, Senatore F, Raffel OC, Lee H, Wackers FJ, et al. (2008) Utility of cardiac biomarkers in predicting infarct size, left ventricular function, and clinical outcome after primary percutaneous coronary intervention (PCI) for ST-segment elevation myocardial infarction. JACC Cardiovasc Interv 1: 415-423. [Crossref]

10. Gollop ND, Dhullipala A, Nagrath N, Myint PK (2013) Is periprocedural CK-MB a better indicator of prognosis after emergency and elective percutaneous coronary intervention compared with post-procedural cardiac troponins? Interact Cardiovasc Thorac Surg 17: 867-871. [Crossref]

11. Thulin $\AA$, Christersson C, Alfredsson J, Siegbahn A (2016) Circulating cell-derived microparticles as biomarkers in cardiovascular disease. Biomark Med 10: 1009-1022. [Crossref]

12. Collinson PO, Gaze DC, Thokala P, Goodacre S (2013) Randomised Assessment of Treatment using Panel Assay of Cardiac markers - Contemporary Biomarker Evaluation (RATPAC CBE). Health Technol Assess 17: v-vi, 1-122. [Crossref]

13. Berezin AE, Kremzer AA, Martovitskaya YV, Berezina TA, Gromenko EA (2016) Pattern of endothelial progenitor cells and apoptotic endothelial cell-derived microparticles in chronic heart failure patients with preserved and reduced left ventricular ejection fraction. EBioMedicine 4: 86-94. [Crossref]

14. Berezin AE, Kremzer AA, Berezina TA, Martovitskaya YV (2015) Pattern of circulating microparticles in chronic heart failure patients with metabolic syndrome: Relevance to neurohumoral and inflammatory activation. BBA Clin 4: 69-75. [Crossref]

15. Berezin AE, Kremzer AA, Cammarota G, Zulli A, Petrovic D, et al. (2016) Circulating endothelial-derived apoptotic microparticles and insulin resistance in non-diabetic patients with chronic heart failure. Clin Chem Lab Med 54: 1259-1267. [Crossref]

16. Berezin AE, Kremzer AA, Berezina TA, Martovitskaya YV (2016) The pattern of circulating microparticles in patients with diabetes mellitus with asymptomatic atherosclerosis. Acta Clinica Belgica: International Journal of Clinical and Laboratory Medicine 71: 38-45.

17. Berezin AE, Kremzer AA, Martovitskaya YV, Samura TA, Berezina TA, et al. (2015) The utility of biomarker risk prediction score in patients with chronic heart failure. Int J Clin Exp Med 8: 18255-18264. [Crossref]

18. Berezin AE, Kremzer AA, Martovitskaya YV, Samura TA, Berezina TA (2014) The predictive role of circulating microparticles in patients with chronic heart failure. $B B A$ Clin 3: 18-24. [Crossref]

19. Berezin AE (2016) Biomarkers for cardiovascular risk in patients with diabetes. Heart 102: 1939-1941. [Crossref]

20. Jeske WP, Walenga JM, Menapace B, Schwartz J, Bakhos M (2016) Blood cell microparticles as biomarkers of hemostatic abnormalities in patients with implanted cardiac assist devices. Biomark Med 10: 1095-1104. [Crossref]

21. Baron M, Boulanger CM, Staels B, Tailleux A (2012) Cell-derived microparticles in atherosclerosis: biomarkers and targets for pharmacological modulation? J Cell Mol Med 16: 1365-1376. [Crossref] 
22. Berezin A, Zulli A, Kerrigan S, Petrovic D, Kruzliak P (2015) Predictive role of circulating endothelial-derived microparticles in cardiovascular diseases. Clin Biochem 48: 562-568. [Crossref]

23. Berezin AE (2015) Impaired Phenotype of Circulating Endothelial-Derived Microparticles: Novel Marker of Cardiovascular Risk. Journal of Cardiology and Therapy 2: 273-278.

24. Amabile N, Gurin AP, Leroyer A, Mallat Z, Nguyen C, et al. (2005) Circulating endothelial microparticles are associated with vascular dysfunction in patients with end-stage renal failure. J Am Soc Nephrol 16: 3381-3388. [Crossref]

25. Berezin A (2016) The Clinical Utility of Circulating Microparticles' Measurement in Heart Failure Patients. J Vasc Med Surg 4: 275-284.

26. Berezin AE, Mokhnach RE (2016) The promises, methodological discrepancies, and pitfalls in measurement of cell-derived extracellular vesicles in diseases. $J$ Biotechnol Biomater 6: 232-239.

27. Nozaki T, Sugiyama S, Koga H, Sugamura K, Ohba K, et al. (2009) Significance of a multiple biomarkers strategy including endothelial dysfunction to improve risk stratification for cardiovascular events in patients at high risk for coronary heart disease. J Am Coll Cardiol 54: 601-608. [Crossref]

28. Giannopoulos G, Vrachatis DA, Oudatzis G, Paterakis G, Angelidis C, et al. (2017) Circulating Erythrocyte Microparticles and the Biochemical Extent of Myocardial Injury in ST Elevation Myocardial Infarction. Cardiology 136: 15-20. [Crossref]

29. Aung HH, Tung JP, Dean MM, Flower RL, Pecheniuk NM (2016) Procoagulant role of microparticles in routine storage of packed red blood cells: potential risk for prothrombotic post-transfusion complications. Pathology doi: 10.1016/j. pathol.2016.10.001.

30. Yao Z, Wang L, Wu X, Zhao L, Chi C, et al. (2017) Enhanced Procoagulant Activity on Blood Cells after Acute Ischemic Stroke. Transl Stroke Res 8: 83-91. [Crossref]

31. Chang AL, Kim Y, Seitz AP, Schuster RM, Lentsch AB, et al. (2016) Erythrocyte Derived Microparticles Activate Pulmonary Endothelial Cells in a Murine Model of Transfusion. Shock [Epub ahead of print]

32. Giannopoulos G, Oudatzis G, Paterakis G, Synetos A, Tampaki E, et al. (2014) Red blood cell and platelet microparticles in myocardial infarction patients treated with primary angioplasty. Int J Cardiol 176: 145-150. [Crossref]

Copyright: (C2017 Berezin AE. This is an open-access article distributed under the terms of the Creative Commons Attribution License, which permits unrestricted use, distribution, and reproduction in any medium, provided the original author and source are credited. 